\title{
Preparation of surfactant-free vinyl polymers by conventional emulsion polymerization using hydrolysable emulsifiers
}

Yoshihiro Itoh*, Fumiya Sahara, Kaori Ozaki, Ryo Akasaka, Akira Teramoto

Functional Polymer Science Course, Division of Chemistry and Materials, Faculty of Textile Science and Technology, Shinshu University, 3-15-1 Tokida, Ueda, Nagano 386-8567, Japan.

Phone: +81-268-21-5489

Fax: +81-268-21-5489

e-mail: yositoh@shinshu-u.ac.jp

\begin{abstract}
Emulsion polymerizations of several vinyl monomers, styrene, methyl methacrylate, butyl methacrylate, butyl acrylate, and vinyl acetate, in water using alkali-hydrolysable cationic surfactants with a betaine ester group, (1-alkoxycarbonylmethyl)trimethylammonium chlorides, as emulsifiers were carried out and properties of the resulting latices and the polymers recovered by hydrolysis and salting out were investigated. There were little influences of the surfactants and monomers used here on the polymerizations, forming stable and monodisperse latices with a mean diameter of ca. $70 \mathrm{~nm}$ and giving a high molecular weight of polymers at high yields. All polymers were precipitated and recovered by adding a small amount of sodium hydroxide into the latex solutions contained little amount of ionic species. Solvent-cast films of the polymers were found to have surfaces as hydrophobic as those for the corresponding pure polymers prepared by bulk polymerization.
\end{abstract}

Keywords Emulsion polymerization, Latices, Cleavable surfactant, Hydrolysis, Betaine ester 


\section{Introduction}

Surfactants play very important roles in both production and storage of polymer latices prepared by emulsion polymerization. On the other hand, the presence of surfactants in products such as latex films and coatings has sometimes unfavorable effects on their performances: e.g., deteriorations of water resistance, quick drying, insulation, adhesive, and other surface properties [1]. Although many attempts to prepare emulsifier-free ('surfactantfree') polymer latices have been reported, their applications in industry are still moderate. This may be partially due to the difficulties in polymerizations [1-3]. Furthermore, it should be noted that, strictly speaking, the majority of these latices are 'surfactant-retarded' ones: given amounts of surfmers (surface-active monomers), hydrophilic monomers, or other additives are still contained in the final products.

Removal of surfactants following conventional emulsion polymerization is another method to prepare 'surfactant-free' polymers [4, 5]. We have recently succeeded in preparation of ionic component-free polystyrene (PSt) by emulsion polymerization using an alkali-hydrolysable cationic surfactant with a betaine ester group, (1tetradecyloxycarbonylmethyl)trimethylammonium chloride $\left(\mathrm{C}_{14} \mathrm{~B}\right)$, as an emulsifier followed by addition of a small amount of alkali [6]. This simple method will have a bright prospect of improving performances of polymer latices.

The purpose of the present study is to demonstrate the applicability of the above method. We have investigated the polymerizations of several vinyl monomers, styrene, alkyl (meth)acrylates, and vinyl acetate, and the properties of the resulting polymer latices and polymers. We find that the polymers have almost the same properties as those of the corresponding surfactant-free polymers prepared by bulk polymerization.

\section{Experimental}

\section{Materials}

Betaine esters $\left(C_{n} B: n=12,14,16 ; n\right.$ is the number of carbon atoms of the sequential alkyl 
chain) are those reported previously [6, 7]. Cetyltrimethylammonium chloride (CTAC) was purchased from Wako Chemical (Osaka, Japan) and used as received. 2,2'Azobis(isobutyronitrile) (AIBN, from Wako Chemical) was recrystallized from methanol. 2,2'-Azobis(2-amidinopropane) dihydrochloride (AIBA, from Wako Chemical) was used as received. Styrene (St), methyl methacrylate (MMA), and vinyl acetate (VAc) were purchased from Wako Chemical, and butyl methacrylate (MBA) and butyl acrylate (BA) were from Tokyo Kasei (Tokyo, Japan), which were distilled under reduced pressure before use. Nuclear Fast Red (NFR: sodium 4-amino-9,10-dihydro-1,3-dihydroxy-9,10-dioxo-2anthracenesulfonate; from Tokyo Kasei) was used as received.

Poly(MMA) (PMMA), Poly(BMA) (PBMA), Poly(BA) (PBA), and poly(VAc) (PVAc) were prepared by conventional bulk polymerization as follows: A mixture of monomer (5 $\mathrm{g}$ ) and AIBN (0.025 g) was heated under argon for $1-3 \mathrm{~h}$ at $65{ }^{\circ} \mathrm{C}$ (for VAc) or $80{ }^{\circ} \mathrm{C}$ (for MMA, BMA, and BA). The resulting polymer solid was then dissolved in a $30 \mathrm{ml}$ of benzene (for PMMA, PBA, and PVAc) or acetone (for PBMA) and precipitated into a $500 \mathrm{ml}$ of methanol. The precipitate was then collected and dried. PSt prepared by bulk polymerization was purchased from Wako Chemical and used as received.

\section{Emulsion polymerizations and recoveries of polymers}

Emulsion polymerizations were carried out by a conventional method using AIBA as an initiator as reported previously [6]. Recoveries of polymers by hydrolysis and salting out were also carried out [6].

\section{Polymer characterization}

Molecular weights (Mw) of PSt were determined by GPC measurements as reported previously [6]. Mws of the other polymers were determined by viscosity measurements: The intrinsic viscosity $([\eta])$ was estimated by extrapolation of the linear part of the concentration dependence of reduced viscosity to a concentration of zero. Mw was then calculated from Mark-Houwink equation: $[\eta]=K \mathrm{Mw}^{a}$. The measurement conditions and Mark-Houwink 
parameters $(K, a)$ were obtained from the literature [8]: $K=5.2 \times 10^{-3} \mathrm{ml} / \mathrm{g}, a=0.76$, in benzene, at $30{ }^{\circ} \mathrm{C}$ for PMMA; $K=18.4 \times 10^{-3} \mathrm{ml} / \mathrm{g}, a=0.62$, in acetone, at $25^{\circ} \mathrm{C}$ for PBMA; $K=6.85 \times 10^{-3}$ $\mathrm{ml} / \mathrm{g}, a=0.75$, in acetone, at $25^{\circ} \mathrm{C}$ for PBA; $K=56.3 \times 10^{-3} \mathrm{ml} / \mathrm{g}, a=0.62$, in benzene, at $30{ }^{\circ} \mathrm{C}$ for PVAc.

Particle size (Z-average size) and distribution (polydispersity index: PDI) of latices, and compositions of the recovered polymers were analyzed as reported previously [6]: the PDI value less than one indicates the narrow distribution of particle size.

Recovered polymer solids were analyzed by ${ }^{1} \mathrm{H}$ NMR spectroscopy as reported previously [6]. Compositions were quantified by measuring the areas of the following peaks in $\mathrm{CDCl}_{3}$ : $\mathrm{C}_{14} \mathrm{~B}, \delta 4.95$ ppm (s, 2H, -CO- $\left.\mathrm{CH}_{2}-\mathrm{N}-\right)$; 1-tetradecanol $\left(\mathrm{C}_{14} \mathrm{OH}\right), \delta 3.62$ ppm (t, $2 \mathrm{H},-\mathrm{C}-$ $\mathrm{CH}_{2}-\mathrm{OH}$ ); PSt, $\delta$ 6.2-7.4 ppm (m, 5H, aromatic); PMMA, $\delta 3.60$ ppm (s, 3H, $-\mathrm{CO}-\mathrm{O}-\mathrm{CH}_{3}$ ); PBMA, $\delta 3.94$ ppm (t, 2H, -CO-O- $\mathrm{CH}_{2}-$ ); PBA, $\delta 4.02$ ppm (t, 2H, -CO-O-CH ${ }_{2}^{-}$); PVAc, $\delta$ 4.82 ppm (broad s, H, $-\mathrm{CH}-\mathrm{O}-\mathrm{CO}-$ ); St (monomer), $\delta 5.23$ and $5.74 \mathrm{ppm}\left(\mathrm{dd}, 2 \mathrm{H},-\mathrm{C}=\mathrm{CH}_{2}\right.$ ); the peaks of other monomers were not detected.

\section{Preparation and characterization of cat films}

Polymer films were cast from 2 wt\% of chloroform solutions in a 32-mm petri dish at room temperature. Adsorption of an anionic dye, NFR, on the polymer films was carried out as follows: A $5 \mathrm{ml}$ of aqueous solution of NFR $(1.4 \mathrm{mM})$ was applied to the surface of the film and left for $3 \mathrm{~h}$ at room temperature, and then the film was washed with water and dried. The film colorization was observed visually. Water contact angles of the films were obtained using the sessile drop method as reported previously [6].

\section{Results and discussion}

\section{Emulsion polymerizations}

Emulsion polymerizations of St were carried out using $\mathrm{C}_{n} \mathrm{~B}$ with different alkyl chain length and CTAC as emulsifiers. The results of polymerizations are summarized in Table 1. In all cases, the conversions reached $90 \%$, no coagulum was formed, and stable latices of 
monodisperse were obtained: the mean diameters were ca. $70 \mathrm{~nm}$ and the PDI values were lower than 0.1. In addition, all the polymers obtained have high molecular weights $\left(>3 \times 10^{5}\right)$. Little dependence of alkyl-chain length of $\mathrm{C}_{n} \mathrm{~B}$ on the polymerizations is probably because the surfactant concentrations (10 mM) are higher than their critical micelle concentrations (CMC) [7], stabilizing the latex particles satisfactorily during polymerization [9]. $\mathrm{C}_{14} \mathrm{~B}$ will be used as a hydrolysable emulsifier hereafter.

Table 2 shows the results of polymerizations for several vinyl monomers. Similar results were also obtained for all monomers: the polymerizations yielded monodisperse latices and high molecular weights $\left(>5 \times 10^{5}\right)$ of polymers at high yields $(>90 \%)$. These results confirm the availability of $\mathrm{C}_{n} \mathrm{~B}$ as emulsifiers in conventional emulsion polymerizations of various monomers.

\section{Hydrolysis and salting out of polymer latices}

The latex solutions obtained were diluted one fifth with deionized water followed by addition of four times excess $\mathrm{NaOH}$ to $\mathrm{C}_{14} \mathrm{~B}$ in the latices to hydrolyze $\mathrm{C}_{14} \mathrm{~B}$. Although the hydrolysis kinetics has not been examined, the majority of the surfactants seem to be hydrolyzed immediately after the addition of $\mathrm{NaOH}(\mathrm{pH}>12)$ based on the fact that the hydrolysis yield of $\mathrm{C}_{14} \mathrm{~B}$ itself at $25{ }^{\circ} \mathrm{C}$ approaches $95 \%$ and $100 \%$ in $10 \mathrm{~min}$ in aqueous solutions of $\mathrm{pH} 9$ and $\mathrm{pH}$ 10, respectively [7] and the hydrolysis is completed in $10 \mathrm{~min}$ (see below). Parallel with the degradation of $\mathrm{C}_{14} \mathrm{~B}$, the latices were instabilized and all polymers precipitated promptly to form lumps. The polymers were also recovered by salting out the latices with 120 times excess $\mathrm{NaCl}$ to $\mathrm{C}_{14} \mathrm{~B}$. The precipitates were rinsed with deionized water three times and then analyzed by ${ }^{1} \mathrm{H}$ NMR spectroscopy. The recovery yields of the precipitates and their compositions are shown in Table 3. Most polymers were recovered almost quantitatively (>90\%). However, the yield of PMMA recovered by salting out and those of PBA by both salting out and hydrolysis were found to be low. In the latter cases, the polymer aggregates and precipitates seem to be easily dispersed or floated in aqueous solutions during rinsing. In fact, the PMMA solids without rinsing were recovered at higher yields. 
PSt recovered by salting out had almost the same composition as in the feed $\left([S t] /\left[C_{14} B\right]=100 / 1\right)$, whereas the other polymers done by it had a decreased content of $C_{14} B$. A possible explanation is that the latter polymers are more flexible or polar than PSt so that a water-soluble surfactant, $\mathrm{C}_{14} \mathrm{~B}$, in the polymer latices may be removed away to some extent in the salting out and rinsing processes. Indeed, the literature values of glass transition temperature $\left(T_{g}\right)$ [8] and polarity $\left(\chi^{P}\right)$ [10] listed in Table 4 confirm that PBMA and PBA are flexible polymers and PMMA and PVAc are polar ones.

As expected, the polymers obtained by hydrolysis contained a distinct amount of a waterinsoluble hydrolyzed product, 1-tetradecanol $\left(\mathrm{C}_{14} \mathrm{OH}\right)$, as an alternative to $\mathrm{C}_{14} \mathrm{~B}$ (Table 3). This clearly indicates that the quantitative hydrolysis of $\mathrm{C}_{14} \mathrm{~B}$ occurs and the recovered polymer solids contain little amount of ionic species. We thus believe that the present method is the easiest and reliable way of removing ionic species from the polymer latices. The content of $\mathrm{C}_{14} \mathrm{OH}$ in the 'hydrolyzed' PBA was higher than expected (1.0 mol\%) probably because the decreased recovery of a flexible polymer, PBA, reversely increased the relative amount of a hydrophobic product, $\mathrm{C}_{14} \mathrm{OH}$, in the precipitate.

\section{Surface properties of polymer films}

It is well known that when polymer films are cast from the latex solutions surfactant molecules in the latices migrate toward the interfaces during film formation, decreasing the film performances, in particular, for paints and other protective coatings [11-13]. In this context, the disappearance of ionic species in the present polymers recovered by hydrolysis would modify the surface properties of the cast films.

The cast films were colored with an anionic dye, FRA. Table 5 summarizes the results of the visual tests. The 'salted-out' PSt film was red colored $(+++)$, indicating the presence of cationic species in the surface. In contrast, the 'hydrolyzed' film was almost transparent just as the 'bulk' one (-). Thus there exists only little amount of ionic species in the 'hydrolyzed' film surface, making the surface hydrophobic.

It is, however, unexpected that the 'salted out' PMMA film was little colored (-). There may be two possible reasons: some portion of $\mathrm{C}_{14} \mathrm{~B}$ is removed away in the salting out and 
rinsing processes (1.0 to $0.6 \mathrm{~mol} \%$ (Table 3$)$ ) and migration of $\mathrm{C}_{14} \mathrm{~B}$ to the PMMA film surface scarcely occurs. The former was confirmed by the fact that the corresponding film made of non-rinsed PMMA is highly colored $(+++)$. It should be noted that the 'hydrolyzed' films made of both rinsed and non-rinsed PMMA are not colored (-) and thus have little amount of ionic species. Similar trends were observed for the other polymer films, though the coloring reflected the polarities of polymers to some extent (Table 5).

The surface wettability will also depend on the presence and concentration of surfactant in the surface. Water contact angles for the above films are shown in Table 6. The obtained values of the 'bulk' polymer films were not necessarily the same as the literature values because contact angles were affected by not only the surface polarity but also the roughness or porosity (i.e., sample preparation method) [17]. Roughly speaking, however, expected tendencies were observed: (1) the 'salted out' films, in particular for non-rinsed polymers, had a smaller value than the 'bulk' ones, indicating the hydrophilic surfaces. (2) the 'hydrolyzed' films had a value as high as for the 'bulk’ ones, indicating the hydrophobic surfaces.

\section{Conclusion}

We have demonstrated that emulsion polymerization using hydrolysable cationic emulsifiers $\left(\mathrm{C}_{\mathrm{n}} \mathrm{B}\right)$ followed by alkali hydrolysis is useful for preparation of various vinyl polymers containing little amount of surfactant. Not only high quality of the resulting polymers but also reactivity of the polymer latices implies many potential applications in polymer latex technology. In particular, the present poly(meth)acrylate latices seem to be the most likely candidates for coating and adhesive materials with water resistance and quick drying. The study along this line is now in progress.

Acknowledgments This work was supported by a Grant-in-Aid for Scientific Research (No. 20550168) and a Grant-in-Aid for Global COE Program from the Ministry of Education, Culture, Sports, Science, and Technology of Japan. 


\section{References}

1. Chern CS (2006) Emulsion polymerization mechanisms and kinetics. Prog Polym Sci 31:443486

2. Caruso F (ed) (2004) Colloids and Colloid Assemblies. Wiley-VCH, Weinheim

3. To N, Wu C (2005) Double roles of stabilization and destabilization of initiator potassium persulfate in surfactant-free emulsion polymerization of styrene under microwave irradiation. Langmuir 21:8520-8525

4. Yamamura S, Nakamura M. Kasai K, Sato H, Takeda T (1991) Synthesis and properties of destructible anionic surfactants with a 1,3-dioxolane ring and their use as emulsifier for emulsion polymerization. Yukagaku 40:1002-1006

5. Mezger T, Nuyken O, Meindi K, Wokaun A (1995) Light decomposable emulsifiers: Application of alkyl-substituted aromatic azosulfonates in emulsion polymerization. Polym Mater Sci Eng $73: 153-154$

6. Itoh Y, Akasaka R, Takahashi K (2008) Preparation of emulsifier-free polystyrene by conventional emulsion polymerization with a hydrolysable emulsifier. J Appl Polym Sci 108:358-361

7. Itoh Y, Akasaka R (2009) Comparison of surface-active properties of (alkyloxycarbonylmethyl)trimethylammonium chlorides and alkyltrimethylammonium chlorides. J Surf Deter 12:101-107

8. Brandrup J, Immergut E.H (eds) (1989) Polymer Handbook, 3rd Ed. Wiley, New York

9. Odian G (2004) Principles of Polymerization, 4th Ed. Wiley, New York, pp 350-371

10. Wu S (1982) Polymer Interface and Adhesion. Marcel Dekker, New York, pp 88-94

11. Hellgren A-C, Weissenborn P, Holmberg K (1999) Surfactants in water-borne paints. Prog Org Coat 35:79-87

12. Steward PA, Hearn J, Wilkinson MC (2000) An overview of polymer latex film formation and properties. Adv Colloid Interface Sci 86:195-267

13. Castro LBR, Almeida A T, Petri DFS (2004) The effect of water or salt solution on thin hydrophobic films. Langmuir 20:7610-7615

14. Khayet M, Vazquez Alvarez M, Khulbe KC, Matsuura T (2007) Preferential surface segregation of homopolymer and copolymer blend films. Surf Sci 601:885-895

15. Tanaka M, Mochizuki A (2004) Effect of water structure on blood compatibility - thermal analysis of water in poly(meth)acrylate. J Biomed Mater Res Part A, 68A:684-695

16. Janorkar AV, Proulx SE, Metters AT, Hirt DE (2006) Surface-confined photopolymerization of single- and mixed-monomer systems to tailor the wettability of poly(L-lactide) film. J Polym Sci Part A: Polym Chem 44:6534-6543

17. Adamson AW, Gast AP (1997) Physical Chemistry of Surfaces, 6th Ed. Wiley, New York 
Table 1 Emulsion polymerizations of St using $C_{n} B$ and CTAC as emulsifiers ${ }^{a}$

\begin{tabular}{llllll}
\hline Surfactant & $\begin{array}{llll}\mathrm{CMC}^{\mathrm{b}} \\
(\mathrm{mM})\end{array}$ & $\begin{array}{l}\text { Conversion } \\
(\%)\end{array}$ & $\begin{array}{l}\mathrm{Mw}^{\mathrm{c}} \\
\left(\mathrm{x} 10^{5}\right)\end{array}$ & $\begin{array}{l}\text { Particle } \\
\text { Diameter }(\mathrm{nm})\end{array}$ & $\mathrm{PDI}^{\mathrm{d}}$ \\
\hline $\mathrm{C}_{12} \mathrm{~B}$ & 7.4 & 90 & 6.2 & 73 & 0.016 \\
$\mathrm{C}_{14} \mathrm{~B}$ & 1.7 & 91 & 4.7 & 72 & 0.016 \\
$\mathrm{C}_{16} \mathrm{~B}$ & 0.36 & 91 & 4.8 & 74 & 0.030 \\
CTAC & 1.5 & 92 & 3.6 & 70 & 0.055 \\
\hline
\end{tabular}

${ }^{\mathrm{a}}[\mathrm{St}]=60 \mathrm{mmol}$; [surfactant $]=0.6 \mathrm{mmol} ;$ [AIBA] $=0.18 \mathrm{mmol}$; polymerization temperature, $60^{\circ} \mathrm{C}$; polymerization time, $6 \mathrm{~h}$

${ }^{\mathrm{b}}$ Ref. 7

${ }^{\mathrm{c}}$ Determined by GPC

${ }^{\mathrm{d}}$ Polydispersity index of particle diameter: ref. 6

Table 2 Emulsion polymerizations of vinyl monomers using $\mathrm{C}_{14} \mathrm{~B}$ as an emulsifier ${ }^{\mathrm{a}}$

\begin{tabular}{llllll} 
& $\begin{array}{l}\text { Polymerization } \\
\text { Polymer }\end{array}$ & $\begin{array}{l}\text { Conversion } \\
(\mathrm{h})\end{array}$ & $\begin{array}{l}\mathrm{Mw}^{\mathrm{b}} \\
\left(\mathrm{x} 10^{5}\right)\end{array}$ & $\begin{array}{l}\text { Particle } \\
\text { Diameter }(\mathrm{nm})\end{array}$ & $\mathrm{PDI}$ \\
\hline PMMA & 1 & 91 & 13 & 57 & 0.101 \\
PBMA & 1 & 96 & 16 & 75 & 0.041 \\
PBA & 5 & 96 & 16 & 69 & 0.035 \\
PVAc & 3 & 91 & 5.6 & 58 & 0.067 \\
\hline
\end{tabular}

${ }^{\text {a }}$ See footnotes in Table 1

${ }^{\mathrm{b}}$ Determined by viscosity measurements 
Table 3 Compositions of polymer solids recovered by hydrolysis and salting out ${ }^{\mathrm{a}}$

\begin{tabular}{lllllll}
\hline & & & \multicolumn{4}{c}{ Component (mol\%) } \\
\cline { 5 - 7 } Polymer & Method $^{\mathrm{b}}$ & Yield (\%) & Polymer & $\mathrm{C}_{14} \mathrm{~B}$ & $\mathrm{C}_{14} \mathrm{OH}$ & Monomer \\
\hline PSt $^{\mathrm{c}}$ & $\mathrm{S}$ & 90 & 97.8 & 0.9 & - & 0.3 \\
& $\mathrm{H}$ & 91 & 98.4 & 0 & 1.0 & 0.2 \\
PMMA & $\mathrm{S}$ & $41(89)^{\mathrm{d}}$ & 96.4 & 0.6 & - & 0 \\
& $\mathrm{H}$ & $91(91)^{\mathrm{d}}$ & 95.9 & 0 & 0.7 & 0 \\
PBMA & $\mathrm{S}$ & 94 & 94.8 & 0.4 & - & 0 \\
& $\mathrm{H}$ & 94 & 94.5 & 0 & 0.9 & 0 \\
PBA & $\mathrm{S}$ & 48 & 91.7 & 0.1 & - & 0 \\
& $\mathrm{H}$ & 32 & 92.4 & 0 & 1.7 & 0 \\
PVAc & $\mathrm{S}$ & $88(95)^{\mathrm{d}}$ & 98.4 & 0.03 & - & 0 \\
& $\mathrm{H}$ & $91(90)^{\mathrm{d}}$ & 97.1 & 0 & 0.9 & 0 \\
\hline
\end{tabular}

${ }^{\mathrm{a}}$ Determined by ${ }^{1} \mathrm{H}$ NMR: recovered polymers are rinsed with water three times

${ }^{b} \mathrm{~S}$, recovered by salting out with aqueous $\mathrm{NaCl}$ (120 times excess to $\mathrm{C}_{14} \mathrm{~B}$ ); $\mathrm{H}$, recovered by hydrolysis in aqueous $\mathrm{NaOH}$ (4 times excess to $\mathrm{C}_{14} \mathrm{~B}$ )

${ }^{\mathrm{c}}$ Ref. 6

${ }^{\mathrm{d}}$ Recovered polymers are not rinsed 
Table 4 Literature values of glass transition temperatures $\left(T_{g}\right)$ and polarity $\left(\chi^{P}\right)$ of polymers

\begin{tabular}{lcl}
\hline Polymer & $T_{g}^{\mathrm{a}}\left(^{\circ}\right)$ & $\chi^{P \mathrm{~b}}$ \\
\hline PSt & 100 & 0.17 \\
PMMA & 105 & 0.28 \\
PBMA & 20 & 0.16 \\
PBA & -54 & 0.10 \\
PVAc & 32 & 0.33 \\
\hline
\end{tabular}

${ }^{\mathrm{a}}$ Ref. 8

b Ref. 10: calculated from the interfacial tension against polyethylene by the harmonicmean equation

Table 5 Coloring of polymer cast films with FRA ${ }^{\text {a }}$

\begin{tabular}{|c|c|c|c|}
\hline Polymer ${ }^{\mathrm{b}}$ & Salting out & Hydrolysis & Bulk \\
\hline PSt & +++ & - & - \\
\hline PMMA & $-\quad(+++)^{\mathrm{C}}$ & $-(-)^{\mathrm{c}}$ & - \\
\hline PBMA & - & - & - \\
\hline PBA & + & - & - \\
\hline PVAc & $++\quad(+++)^{\mathrm{c}}$ & $+\quad(+)^{\mathrm{c}}$ & - \\
\hline
\end{tabular}

a Determined visually: +++, highly colored; ++, colored; +, slightly colored; -, not colored; films are rinsed with water three time b Polymers are ones recovered by salting out and hydrolysis and one prepared by bulk polymerization

${ }^{\mathrm{c}}$ For non-rinsed polymer films 
Table 6 Water contact angles $\left(^{\circ}\right)$ of polymer latex films

\begin{tabular}{lccc}
\hline Polymer & Salting out & Hydrolysis & Bulk \\
\hline PSt & 12 & 88 & $90(90)^{\mathrm{b}}$ \\
PMMA & $67(44)^{\mathrm{a}}$ & $73(73)^{\mathrm{a}}$ & $72(74)^{\mathrm{b}}$ \\
PBMA & 77 & 83 & $83(88)^{\mathrm{b}}$ \\
PBA & 104 & 110 & $104(81)^{\mathrm{c}}$ \\
PVAc & $62(16)^{\mathrm{a}}$ & $72(71)^{\mathrm{a}}$ & $72(61)^{\mathrm{d}}$ \\
\hline
\end{tabular}

${ }^{\mathrm{a}}$ For non-rinsed polymer films

${ }^{\mathrm{b}}$ Ref. 14

${ }^{\mathrm{c}}$ Ref. 15

${ }^{d}$ Ref. 16 